Santofimio-Ortiz, R. (2018). El pensamiento de Antonio Gramsci en América Latina y Colombia. Revista de Antropología y Sociología: VIRAJES, 20 (1), 177-196. DOI: 10.17151/rasv.2018.20.1.9

\title{
EL PENSAMIENTO DE ANTONIO GRAMSCI EN AMÉRICA LATINA Y COLOMBIA*
}

\section{RODRIGO SANTOFIMIO-ORTIZ**}

Recibido: 08 de octubre de 2017

Aprobado: 15 de diciembre de 2017

\footnotetext{
* El presente artículo con modificaciones y adiciones sustanciales fue previamente publicado en el libro: Antonio Gramsci y la sociología contemporánea (2015). Agradezco a la Universidad de Caldas el permiso para su publicación en la revista.

** Magíster. Profesor Titular, Universidad de Caldas, Manizales, Colombia.

E-mail: rodrigo.santofimio@ucaldas.edu.co. 으 ORCID: 0000-0002-6671-0887. Google Scholar
} 


\title{
Resumen
}

Este ensayo muestra que el pensamiento de Antonio Gramsci replicó en varios países de América Latina como fuente de comprensión de las nuevas realidades socio- políticas que vivían los países; en el caso colombiano, si bien la presencia del gramscismo es relativamente comparable a la apropiación argentina, esa "presencia" se inserta primariamente en requerimientos culturales, pero también Gramsci fue retomado con pretensiones para la praxis política, en un ambiente socio-político altamente crispado de la lucha armada y la virulencia de los movimientos sociales; el ensayo, entonces, pretende una comprensión crítica del proceso de apropiación de los "sistemas de ideas", los cuales no se explica únicamente a partir de la difusión de las obras, sino que también tienes que ver con las características de los escenarios, así como de los obstáculos y medios utilizados; finalmente, la metodología tiene que ver con una postura hermenéutica, consultas y revisión crítica de fuentes primarias y secundarias.

Palabras clave: Gramsci, América Latina, Colombia, gramscismo, revista Mito, sociedad civil.

\section{THE THINKING OF ANTONIO GRAMSCI IN LATIN AMERICA AND COLOMBIA}

\begin{abstract}
This essay shows that the thinking of Antonio Gramsci replicated in several countries of Latin America as a source of understanding of the new socio-political realities that the countries lived. In the Colombian case, although the presence of gramscianism is relatively comparable to the Argentine appropriation, this "presence" is inserted primarily in cultural requirements, but Gramsci was also resumed with pretensions for political praxis in a highly tense socio-political environment of the armed struggle and the virulence of social movements. This paper then, seeks a critical understanding of the process of appropriation of the "systems of ideas", which is not only explained by the diffusion of the works, but also has to do with their appropriation in terms of scenarios as well as the obstacles and means used. Finally, the methodology has to do with a hermeneutic posture and consultation and critical review of primary and secondary sources.
\end{abstract}

Key words: Gramsci, Latin America, Colombia, gramscismo, journal Mito, civil society. 


\section{Introducción}

L as pistas acerca de la trayectoria del pensamiento de Antonio Gramsci en América Latina, en principio, suponen dos posibilidades: la primera, seguir la trayectoria sobre la difusión de su obra (sus textos escritos) no solo en el ámbito directamente implicado sino su inserción en las izquierdas y posiblemente al interior de ciertos círculos intelectuales y académicos. Este esfuerzo podría traducirse, de acuerdo al lenguaje de Aricó (1988), en una especie de "geografía del gramscismo en América Latina". Lo anterior, será el esfuerzo que pretendemos llevar a cabo en el presente texto. Sin embargo un esfuerzo más sistemático tiene que ver con aprehender y comprender, más allá de la difusión del pensamiento gramsciano, sobre su apropiación y los escenarios de crítica que haya producido y las posturas y contraposturas de dicha recepción.

Aricó muestra que en México a Gramsci se lo concebía, por lo menos a los ojos de Agustín Cueva (1998), "como un revisionista y la escoria del oportunismo" (p. 36) ${ }^{1}$; es posible que esta posición esgrimida por el connotado autor mexicano, la hayan asumido otros dirigentes y miembros conspicuos de los partidos comunistas de algunos países —en especial, en aquellos partidos más aferrados dogmáticamente a los esquemas leninistas y estalinistas-. Este fue el caso colombiano, del cual nos ocuparemos más adelante.

No obstante, la repulsa que pudiera ocasionar Gramsci en las huestes de los partidos comunistas anclados en un férreo estalinismo, su pensamiento suscitaría la expectativa por su frescura y su aire renovador que -más allá de su orientación para fines estrictamente de estrategia políticaposibilitaba nuevas apropiaciones y comprensiones de los fenómenos latinoamericanos. Esta es, por lo menos, la idea que traduciría Aricó (1998) al decir que "los cuadernos (de Gramsci) se nos vuelven accesibles sólo a condición de anteponerlos a nuestro propio principio constructivo" (p. 30).

La otra posibilidad de la apropiación e interpretación del pensamiento de Gramsci, en el concierto latinoamericano, tendría que ver con la intelectualidad y los agentes culturales de la región puesto que

quienes vivimos la posesión de la cultura con un agudo sentimiento de culpa, "a partir de él" (Gramsci), podíamos reencontrarnos con lo que efectivamente éramos, con nuestras grandezas y servidumbres

\footnotetext{
${ }^{1}$ Paradójicamente Palmiro Togliatti, en un escrito de homenaje a Gramsci recién enterado de su muerte, afirma que Gramsci concebía al trotskismo como la putain du fascisme (Gramsci, 1953).
} 
[...] (pues), por primera vez la cultura era colocada allí donde debía estar, como una dimensión insuprimible de la acción política. (Aricó, 1988, p. 23-24)

Claro está que Aricó (1988) expresa la necesidad de reencontrar "al Gramsci" que muestra el papel del intelectual, "más que inestable y sospechoso", compañero de ruta del proletariado y su dimensión insuprimible de la acción política: "el intelectual orgánico".

\section{Recepción en América Latina}

Ahora bien, ¿qué pasó entonces con la difusión del gramscismo en América Latina? El conocimiento de las obras de Gramsci, dice Aricó (1988), fue de temprana data en el subcontinente: ya que fue precisamente en América Latina donde los Cuadernos de la cárcel aparecieron por primera vez traducidos no solo al español, sino también al portugués. En efecto, los Quaderni dal carcere se publicaron parcialmente en Buenos Aires entre 1958 y 1962; mientras que en Brasil aparecieron en versión portuguesa entre 1966 y 1968². Para el caso mexicano, Aricó (1988) afirma que los Cuadernos de la cárcel llegaron en cuatro tomos: 1981, 1984 y 1986, traducidos del italiano por Ana María Palos y revisados por José Luis Gonzales. Cabe advertir que Aricó (1988) olvida que algo menos de una década antes Manuel Sacristán Luzón introducía para México su Antología (1970) en una cuidadosa selección, traducción y notas de los artículos más tempranamente publicados por el “joven Gramsci" en los periódicos Avanti! y Il Grido del Popolo (1911-1917); así como las publicaciones "del Gramsci más político y maduro" (19171922), antes de su viaje a la Unión Soviética. Aparecen, por último, una serie de textos de los Cuadernos de la cárcel (1922, 1930 y 1931) y algunas cartas escritas antes y después de sus años de reclusión; tal como dice Domingo Curto (1998): Sacristán Luzón no solo fue un pionero en la difusión de la filosofía de Gramsci en España (1958), sino también en la difusión de su pensamiento en México; culminando para "Sacristán un proceso de trabajo intelectual muy intenso en el cual hubo de conocer a fondo y al completo la obra de aquél (Gramsci) publicada hasta ese momento" (p. 16).

En el caso de la Argentina fue Héctor Pablo Agosti (pensador, ensayista y miembro conspicuo del Partido Comunista en los 50) el que dirigió la publicación de los Cuadernos de la cárcel para la Editorial Lautaro

\footnotetext{
${ }^{2}$ Resulta extraño que Herrera (2009) afirme que "sólo hasta 1975 no se disponía aquí (América Latina), ni tampoco en Europa de una edición rigurosa de la obra completa. Este era el signo de la misma Italia, aunque se filtraran avances de aquel trabajo editorial" (p. 21-22).
} 
con traducciones o prólogos del mismo Aricó (1998), el que agrega: “en los críticos años cincuenta pudimos acceder tempranamente a Gramsci, porque Agosti nos desbrozó el terreno" (p. 32). En esa oportunidad, la Editorial Lautaro también publicaría: Materialismo histórico y la filosofía de Benedetto Croce (1958), traducción de Isidoro Flaumbaum y prólogo de Agosti; Los intelectuales y la organización de la cultura (1960), traducción de Raúl Sciarreta; Literatura y vida nacional (1961), traducción de José Aricó con prólogo de Héctor Pablo Agosti y Notas sobre Maquiavelo, sobre Política y sobre el Estado moderno (1962), traducción, prólogo y notas de José Aricó; es de agregar que para abril de 1963 se iniciaba en Córdoba (Argentina) la publicación de una revista trimestral de ideología y cultura, de clara inspiración gramsciana, bajo el título Pasado y Presente, 'destinada' "a examinar las experiencias civiles y morales, para dar una expresión no sólo teórica sino también política" (Aricó, 1998, p. 63); partiendo del principio gramsciano de que "la crítica sobre el pasado, permite su superación”. Herrera (2009), afirma que la revista la dirigió el mismo Aricó desde 1968 a través de la Editorial Siglo XXI.

En cuanto a México, a propósito de la obra de Gramsci, Córdova -en un interesante artículo publicado en la revista Nueva Sociedad sobre el centenario del nacimiento del filósofo y político italiano- plantea que con la explosión del conflicto Chino-Soviético —en los 60 - se fijarían pautas acerca de esa recepción; pues lo cierto fue que Gramsci entró en algunos ambientes académicos con jóvenes profesores marxistas sin militancia política muchos de los cuales habían estudiado en Europa y algunos, incluso, en Italia, "con una visión del marxismo en la que era común y necesaria la referencia a Gramsci" (Córdova, 1991, p. 161). No obstante, advierte Córdova (1991), ese Gramsci recepcionado en México fue a través de Althusser: "precedido de una pésima fama no sólo de "crociano" e "historicista" sino hasta de "reformista"" (p. ); lo cierto fue que, curiosamente, Córdova admite que Gramsci comenzó a cobrar fuerza en la medida en que todo el mundo iba olvidándose de Althusser.

Ello era ya evidente a mediados de los 70. Pero lo más importante, desde luego, fue la proliferación de estudios marxistas sobre la realidad mexicana y su cada vez más difusa ligazón con la obra y el pensamiento de Gramsci. Sus grandes conceptos y preocupaciones (sociedad civil, sociedad política, hegemonía, bloque histórico, reforma moral e intelectual de la sociedad, el príncipe moderno, el mito popular de inspiración maquiaveliana, etc.), se fueron convirtiendo en referentes teóricos indispensables en el estudio de la nación mexicana y de su historia. (Córdova, 1991, p. 164) 
En Brasil, Coutinho (1991) plantea que Gramsci llegó a comienzos de los 60: "el marxismo brasileño de la época, era particularmente débil inclusive comparándolo con otros marxismos latinoamericanos y tenía como principales fuentes "teóricas" los manuales soviéticos de "marxismo leninismo"" (p. 104); el mismo autor, Coutinho, se puede considerar referencia indiscutible en la recepción del pensamiento gramsciano en Brasil (Hobsbawm, 2011). Si bien, dice Coutinho (1991), eran publicaciones culturales influenciadas o ligadas al Partido Comunista Brasileño, no se percibía "el agudo teórico del Estado ampliado" y de la revolución socialista en Occidente, ni siquiera el investigador de las formas no clásicas de transición para la modernidad capitalista (la problemática de la revolución pasiva)" (p. 105). En síntesis, alude Coutinho (1991), se trataba, entonces, de un Gramsci apropiado "en los terrenos de la filosofía, de la estética y de la crítica cultural" (p. 105); como también parece plantearse para el caso colombiano, un Gramsci sustraído de la "práctica-política" puesto que esta "era atribución de la dirección del Partido de dar la última palabra en las cuestiones específicamente políticas" (Coutinho, 1991, p. 106).

Las publicaciones de Gramsci, en el contexto - período relativamente 'liberal' de la dictadura (1964-1968)—, alude Coutinho (1991), aparecen en portugués: Las cartas de la cárcel y la edición temática de los Cuadernos, en cuanto al volumen sobre Il materialismo storico (que por el temor a la censura, el editor brasileño resolvió llamar Concepción dialéctica de la historia), fueron publicados a comienzos de 1966; en un segundo momento, en 1968, sería la ocasión de Los intelectuales y la organización de la cultura y una edición reducida de Literatura y vida nacional; solamente, agrega Coutinho (1991), "en una tercera etapa es que vendrían a la luz los escritos sobre Maquiavelo, sobre Pasado y Presente" (p. 107). Empero, Gramsci, entonces, concluye Coutinho (1991), tenía una finalidad clara: presentar al lector una dimensión del autor italiano como "filósofo y crítico literario, en el cual la dimensión estrictamente política tenía un peso secundario" (p. 107). Para mediados de los 70, Gramsci fue retomado nuevamente e "ingresa a la universidad". En este sentido dice Coutinho (1991), "de las siete monografías sobre Gramsci escritas y publicadas como libro, por lo menos cinco sean tesis universitarias" (p. 108); y, en los 80, sobre todo, fueron realizadas importantes investigaciones universitarias "bajo la influencia de categorías o problemáticas gramscianas, en dominios que van desde la antropología hasta la sociología y la ciencia política, abarcando temas tan variados como la cultura popular, el fenómeno religioso, cuestiones pedagógicas o de política y servicio social" (Coutinho, 1991, p. 113).

La difusión de Gramsci en Chile, dice Faletto (1991), "no era muy notoria. Circulaba en algunas ediciones apartes de la obra hechas por 
editorial Lautaro de Argentina, poco más tarde algunas ediciones españolas, por ejemplo, las ediciones Península, 1967; Siglo XXI de México, publicó una antología" (p. 90); una de las pocas publicaciones chilenas, alude Faletto (1991), fue la selección realizada por Osvaldo Fernández, que editada por la editorial Nascimento en 1971, y que recibió como título: Maquiavelo y Lenin. Notas para una teoría política marxista y que en su gran parte corresponde a lo que en la edición togliattiana escribió bajo el título de Notas sobre Maquiavelo. Sobre política y sobre el Estado Moderno" (p. 91). Los temas prevalentes en la recepción del gramscismo en Chile tienen que ver con el intelectual orgánico, el problema de la hegemonía y el bloque histórico (Faletto, 1991), aunque esta apropiación temática se hizo en función de necesidades "político-prácticas"; además de leerse en clave 'teórica' y desde Lenin; lo paradójico de esta recepción o de "los usos de Gramsci”, de acuerdo a la expresión de Portantiero (como se citó en Faletto, 1991), produjo antes y después de la dictadura una renovación y una resignificación de Gramsci. Es decir que "no sólo se leyó en clave leninista, sino también anti-leninista" (Faletto, 1991, p. 97); así pues, al enfrentarse a la dictadura de derecha, para la izquierda chilena, "era necesario también discutir la dictadura proletaria, asumiendo una posición ética, en defensa de los derechos humanos, lo que llevaría posteriormente a replantear el concepto mismo de hegemonía y la formación de consensos" (Faletto, 1991, p. 97).

En Bolivia, con una tradición importante de presencia de la sociedad civil (Calderón, 1991), Gramsci fue asumido a través de una "lectura instrumental" para la elaboración conceptual del MIR y sus intelectuales. Calderón (1991) muestra que allí en esos movimientos sociales (mineros, indígenas y campesinos), propios de la sociedad civil boliviana, era fuerte la influencia leninista y trotskista, lo que afectaba pensar en la pluralidad ciudadana, así como de las características étnicas y nacionales de la sociedad boliviana" (p. 159); a mediados y fines de los 70, dice Calderón (1991),

la difusión y discusión de textos de Gramsci, tanto por ediciones argentinas como mexicanas, sobresaliendo la colección de Pasado Presente y, muy especialmente, el texto de Juan Carlos Portantiero y la traducción del libro de Portelli sobre el concepto de "bloque histórico". (p. 159-160)

En suma, en un contexto de transición del autoritarismo a la democracia en Bolivia, dice Calderón (1991), se "elaboraron y discutieron tesis gramscianas, ya sea en la universidad, donde llegó existir un semillero permanente sobre Gramsci, como en algunos textos académicos de especialistas" (p. 160). 
Para el caso de Cuba, Acanda (1992) muestra que Gramsci "comienza a ser conocido" entre 1959 y 1973. Dos textos suyos son publicados: El materialismo histórico y la filosofía de Benedetto Croce, en 1966; y la Antología, preparada por Manuel Sacristán, en 1973. Gramsci también es incorporado a los programas de enseñanza de filosofía marxista en algunos centros de educación superior. No obstante, desde 1973 hasta 1986, "sobre Gramsci -al igual que sobre otras figuras no aceptadas por el marxismo de corte stalinista-, se extiende un 'manto de silencio'; desaparece de los programas de estudio y se acalla todo eco de su repercusión a nivel social" (Acanda, 1992, p. 358).

Los peruanos reconocen la década del 70 como de gran influencia gramsciana en la universidad, en el periodismo y la vida sindical (Mejía, 1987). Sin embargo hay que tener en cuenta que estas últimas indicaciones, más que subrayar cierta influencia de Gramsci al igual que las interpretaciones que se hacían de su obra, no muestran las posibles producciones o traducciones para la difusión de su pensamiento.

En lo que sí parecen coincidir Mejía (1987) y Herrera (2009), es que Gramsci hizo su inserción en América Latina entre los 60 y 80 de cara a las luchas obreras y campesinas. De igual forma hizo notables progresos en el campus universitario latinoamericano no solo en México (UNAM) ${ }^{3}$ y Centroamérica, sino también en Suramérica antes y después de la caída definitiva de las dictaduras; lo que parece explicar este redescubrimiento de Gramsci, en América Latina, tiene que ver con lo que Castañeda (1995) denomina "la división tradicional de Estado y la sociedad civil" que volvía a hacer su aparición a través de los "nuevos movimientos" que surgieron en buena medida exteriores al Estado. La reinterpretación gramsciana de Marx y Hegel, agrega Castañeda (1995):

fue una elaboración filosófica extraordinariamente positiva, porque rompía con la máxima que se atribuía al marxismo-leninismo según la cual toda política se reducía al nivel del Estado, y la única política con la que valía la pena comprometerse era aquella que involucraba al propio Estado. (p. 234-235)

\footnotetext{
${ }^{3}$ Herrera (2009) dice que en esa oportunidad "se corresponde al profesor Francisco Piñón Gaytán, alrededor del Círculo de Estudios Sociales Antonio Gramsci y unas conferencias periódicas" (p. 27).
} 


\section{Recepción en Colombia}

¿Qué aconteció con la difusión del pensamiento de Antonio Gramsci en Colombia? Los trabajos en la perspectiva de responder a dicho interrogante no se conocen. En su lugar se ha pretendido responder al posible aporte conceptual y político que haya podido producir el gramscismo en el ámbito de la estrategia política de los movimientos sociales (obreros, campesinos y organizaciones barriales o sectoriales como el movimiento pedagógico, por ejemplo) y también en el ámbito académico-universitario. Esta es una perspectiva interesante que inaugura Mejía (1987), mostrando las dificultades de asumir al gramscismo en los 70 dado "un señalamiento de social demócrata que pesaba sobre el fundador del PC italiano" (p. 100). En la década siguiente descienden las luchas obreras y campesinas para dar paso al auge del movimiento cívico. Fue este nuevo escenario, así como la irrupción de organizaciones de origen popular con reivindicaciones urbanas y una relativa cualificación de sectores medios, en donde el pensamiento gramsciano comienza a tener importancia e influencia en Colombia; esa influencia la lleva a cabo en el cambio de comportamiento político del magisterio a través del movimiento pedagógico para replantear su consigna estratégica, al concebir que "solo cambiando el sistema cambiará la Educación [...] era una forma alternativa de pensar y hacer real el problema cultural" (Mejía, 1987, p. 99-101).

Por su parte, el otro autor, Herrera (2009), en esa misma perspectiva, muestra que las primeras referencias a Gramsci fueron hechas por el crítico literario y ensayista cultural Carlos Rincón a través de un ensayo, en Letras Nacionales, publicado en la segunda mitad de los 60. Después, con la activación de los movimientos estudiantil y campesino extendidos hasta la coyuntura populista de los 70, otra fue la recepción de Gramsci debido a que "inspiró la política de los nuevos ensayos organizativos de la izquierda socialista" (Herrera, 2009, p. 29).

Herrera plantea también que la revista El Manifiesto, órgano de difusión de la Unión Revolucionaria Socialista -URS—, publicaba como proyecto editorial el pensamiento de Gramsci; buscando el entendimiento de la historia nacional. Adicional a lo anterior, Herrera (2009) afirma que "un puñado de estudiosos del pensador sardo encontramos un refugio en las universidades y centros de acción social y política. Uno de tales espacios fue el círculo de crítica jurídica Antonio Gramsci, con centro en la Universidad Libre de Bogotá" (p. 30); cabe mencionar, finalmente, la resistencia que se hacía desde el Partido Comunista a la interpretación gramsciana, que disminuiría en los años 80 con el derrumbe de la propuesta eurocomunista" (Herrera, 2009, p. 34). 
Como se ha podido observar el interés de estos dos autores fue evidenciar el aporte conceptual y analítico del pensamiento gramsciano en las organizaciones sociales y políticas, pero sin ninguna alusión a la difusión de su pensamiento vía traducción o sencillamente la publicación o reproducción de sus obras en Colombia.

De nuestra parte, y como ya se dijo, al parecer una de las primeras intenciones de difusión de la obra de Gramsci se hizo en la revista cultural Mito (Bogotá). A manera de artículo aparece, para 1956, en el número 6 de la revista, "Literatura funcional"; artículo de seis páginas, que según la revista pertenecía a sus Cuadernos de la cárcel y había sido tomado de Letteratura e vita Nazionale (publicado por la editorial Einaudi, en la ciudad de Milán, correspondiente a la $3^{\text {a }}$ edición de 1953); la traducción para la revista la hizo Affan Buitrago. Como sabemos, el tema de la literatura para Grasmci (1972) se ubica en un contexto más general y estaba referido a las novelas folletinescas y al gusto popular.

El artículo aludido comienza preguntándose: ¿qué es lo que correspondería en literatura al 'racionalismo' tan empleado en la arquitectura? ¿La literatura como otras artes debe inscribirse en lo que se denomina racionalismo, es decir, literatura funcional?

Cuando el arte, especialmente en sus formas colectivas, va dirigido a crear el gusto masivo, a elevar este gusto, no puede llamarse "industrial" porque es desinteresado, es decir, arte. Me parece que el concepto de "racionalismo" en arquitectura, esto es, funcionalismo, es muy fecundo en consecuencias, en principios y normas de política cultural; no es casual que haya nacido precisamente en estos tiempos de "socializaciones" (en el sentido lato), y de intervención de las fuerzas centrales para organizar las grandes masas contra los residuos de individualismo y de estéticas individualistas en la política cultural. (Gramsci, 1956, p. 408-409)

Pero, ¿qué es una obra de arte?

El lenguaje 'literario' dice Gramsci, está estrechamente ligado a la vida de las muchedumbres nacionales y se desarrolla lenta y molecularmente de acuerdo con el desarrollo propio de cada grupo nacional; y si se puede decir que cada grupo social tiene su lengua puede sin embargo anotarse que entre la lengua popular y la de las clases cultas se da un continuo intercambio y se presente una continua adherencia. (Gramsci, 1956, p. 409) 


\section{el teatro,}

El ejemplo ilustrativo al que alude Gramsci (1956) puede darse en

[...] aunque algunos no lo llamen arte, sino recreación de carácter mecanicista, esa observación resulta falsa, en el sentido de que en la representación teatral, el elemento artístico no está solamente en el drama, desde el punto de vista literario; el creador no es únicamente el escritor del drama, aunque interviene decididamente en la representación teatral con las palabras y la didascalia que limitan el arbitrio del actor y del director; pero realmente, en la representación, el elemento literario ofrece ocasiones a nuevas creaciones artísticas que por complementarias o critico-interpretativas están llegando a ser cada vez más importantes: estos nuevos órdenes de creación son la interpretación del actor y el complejo escénico creado por el director. Admitido que sólo la lectura repetida puede permitir gustar el drama de la misma manera que el autor lo produjo, la conclusión es lógicamente la siguiente: una obra de arte es tanto más "artísticamente" popular cuanto más adhiere en su contenido moral, cultural, sentimental, a la moralidad, la cultura, los sentimientos nacionales, y no extendidos estos como una cosa estática sino como una actividad en perpetuo desenvolvimiento. (p. 410)

Finalmente, ¿puede haber un arte educador?

$\mathrm{El}$ arte es educador, en cuanto arte, considerado puramente, pero no en cuanto arte educador o docente porque en tal caso no es nada, y la nada no puede educar [...] Cuando una obra de poesía o un ciclo de obras poéticas se ha formado, es imposible continuar dicho ciclo en el estudio, la imitación y las variaciones en torno a aquélla obra: por esta camino se obtendrá solamente lo que se ha llamado "escuela poética", o sea la clientela de los epígonos. La poesía no genera poesía, aquí no tiene lugar la partenogénesis; se requiere la intervención de un elemento músculo, más poderoso, es decir o de eso que es real, pasional, práctico, moral. Los más altos críticos de poesía aconsejan, en este caso, no recurrir a recetas literarias, sino, como se dice, a "rehacer el hombre". Reconstruido, renovado el hombre, refrescado el espíritu, surgida una nueva vida afectiva, de ahí surgirá, sí surge, una nueva poesía. (Gramsci, 1956, p. 411)

Esta observación, agrega Gramsci (1956),

puede reputarse propia del materialismo histórico. La literatura no genera literatura, etc., etc., es decir, las ideologías no crean ideologías, las superestructuras no generan superestructuras, sino tal vez como 
herencia inerte y pasiva: ellas se producen, no por partenogénesis sino por la intervención del elemento músculo, la historia, la actividad revolucionaria, que crea un nuevo hombre, vale decir, nuevas relaciones sociales. (p. 411)

De igual forma, y de acuerdo con Gramsci (1956),

la dialéctica en Pirandello [...] es lo ilustrativo de cómo interviene 'el elemento músculo' en la concepción de la obra de arte y también de su funcionalidad y no el simple 'arte industrial': La importancia de Pirandello me parece de caracteres intelectuales y morales, esto es, culturales, más que artísticos: él ha buscado introducir en la cultura popular la dialéctica de la filosofía moderna, en oposición a la manera aristotélico-católica de concebir "la objetividad de lo real". Lo ha hecho como puede lograrse en el teatro y del modo como podía hacerlo el mismo Pirandello: esta concepción dialéctica, de la objetividad se presenta al público como aceptable, porque es personificada por caracteres excepcionales bajo apariencias novelísticas, en lucha paradojal contra el sentido común o el buen sentido. Mas ¿podría ser de otro modo? Sólo así los dramas de Pirandello muestran menos el carácter de diálogos filosóficos de que adolecen bastante, ya que los protagonistas deben "explicar y justificar" demasiado frecuentemente el nuevo modo de concebir lo real [...]. (p. 413)

Hemos citado in extenso el artículo de Gramsci publicado en la revista Mito (1956) por la exposición argumentativa y la premisa que orienta el análisis: esto es, sobre las posibilidades de "crear un gusto masivo, con pretensiones artísticas"; Gramsci, sin duda, en estos pasajes, pretendía discutir las pretensiones oficiales para la constitución de un arte no solo fascista sino también socialista habida cuenta de la realidad que emergía tras los muros de la prisión.

La revista Mito fue fundada en 1955 por el poeta Jorge Gaitán Durán y Hernando Valencia Goelkel para, según sus gestores, "promover un despertar de la inteligencia colombiana, de fructificar las fuerzas latentes que no habían sucumbido al desierto, de darles la palabra y un motor que las mantuviera vigilantes" (Gutiérrez, 2005, p. 4); con la revista Mito se pretendía, teniendo como referencia la experiencia de la revista Les Temps Modernes — que dirigía el filósofo francés Sartre en París, sin adherirse a una determinada ideología ni a determinados intereses y vanidades políticas-, "la convivencia intelectual y, consecuentemente, la social" (Gutiérrez, 2005, p. ); dicha convivencia intelectual estaba enmarcada en una apertura al mundo, agrega Gutiérrez (2005), testimoniada en la búsqueda 
de conocimiento y asimilación de la cultura universal; de la que acunó y expresó la consciencia del mundo contemporáneo, que de por sí ponía en tela de juicio y hasta desplazaba el aislamiento provinciano y mediocre con el que la usurpadora clase dirigente mantenía al país en un estado de pomposa y violenta inercia.

Sin embargo, no todos los intelectuales coincidían con esa crítica. Darío Mesa (1995), por su parte, concebía a la revista Mito como "la revista de las clases moribundas"; debido a que,

unas clases que, identificadas por Mito con el hombre, no son sino un hombre histórico, que empieza a desaparecer: el burgués, el terrateniente y también el pequeño burgués que está muriendo bajo los golpes del gran capital monopolista [...]. Por su parte, la pequeña burguesía, por sus condiciones de existencia, es aliada natural del proletariado o perece por asfixia o por los golpes directos. Todo esto viene a cuento porque lo que Mito ha hecho hasta hoy es buscar una expresión intelectual de la condición ideológica de las clases moribundas en la sociedad moderna. (p. 281-282)

Es de advertir que en la crítica hecha por Mesa se le reclamaba también a la revista Mito porque supuestamente estaba ofreciendo el formalismo (la pura literatura) sin detenerse a comprobar isi es cierto que las formas pueden ser restauradas o creadas sin la dinamicidad que les confieren sus contenidos? La dimensión histórica auténtica, se respondía Mesa (1995), "dice Mito que se les devuelve a las palabras con el análisis, pero este es precisamente lo que la revista elude" (p. 282-283).

Resta decir el desconocimiento que Mesa (1995) tiene de Gramsci de acuerdo al soporte analítico y argumental con que encara su crítica, citando en principio a Hegel — creador de la dialéctica- a Marx y Engels —creadores del marxismo- y seguidamente a sus continuadores, Lenin y Stalin, para concluir que "han estudiado las tendencias de la realidad en que vivieron y nadie ha podido comprobar seriamente que se hubieran equivocado" (p. 288).

Dejando a un lado la revista Mito, solo hasta los 60 saldría un librito intitulado: Al partido, cuyos autores aparecen respectivamente como Lenin y Gramsci (1975). El librito fue publicado por la Editorial Lealon, de Medellín, como editor Norman Bethome y distribución de La Pulga editorial.

$\mathrm{Al}$ analizar el librito de difusión de la obra de Gramsci, es importante detenernos en un subrayado que hizo un lector anónimo al texto Contra el pesimismo (L'Ordine nuovo, el 15 de marzo de 1924): 
[...] tuvimos que transformar a nuestros grupos, en el hecho mismo de su constitución, de su enrolamiento, en destacamentos para la guerrilla, para la más atroz y difícil de las guerrillas en la que jamás clase obrera tuvo que combatir. Sin embargo lo logramos: el partido se constituyó y se constituyó fuertemente [...]. (Lenin y Gramsci, 1975, p. 12)

En el mismo librito, y a manera de introducción, aparece la siguiente nota:

adherirse a un movimiento quiere decir asumir una parte de la responsabilidad de los acontecimientos que se preparan, convertirse en artífices directos de esos acontecimientos mismos. Un joven que se inscribe en el movimiento socialista juvenil realiza un acto de independencia y de liberación. El agua es agua pura y libre cuando fluye entre dos orillas de un arroyo o de un río, no cuando está caóticamente dispersa por el suelo ni cuando se difunde enrarecida por la atmósfera. Así, el que no sigue una disciplina política es materia en estado gaseoso o ensuciada por elementos extraños: por tanto, inútil y dañosa. La disciplina política hace que precipiten esas impurezas y da al espíritu su metal mejor, una finalidad a la vida, sin la cual no valdría la pena vivirla. Todo joven proletario que sienta lo que pesa el fardo de la esclavitud de clase debe realizar el acto inicial de su liberación.

Como se puede observar, en la nota anterior, para el lector desprevenido, Gramsci estaría insistiendo en la necesidad del Partido - particularmente, en una etapa de su vida juvenil-. Sin embargo gran parte de la 'recopilación' que aparece en este librito, de 69 páginas, está referida a los artículos de Lenin publicados en el periódico Pravda. Como se muestra para otros escenarios de América Latina, a propósito de la obra y el pensamiento gramsciano, su recepción estaba precedida a través del 'leninismo' —en especial, en lo referente a su producción en pleno auge del proceso revolucionario en la Rusia zarista-.

La otra publicación de esos años se titula: El Príncipe, de Nicolás Maquiavelo, con comentarios de Antonio Gramsci, de Ediciones Pepe (Medellín); sin fecha de edición, aunque se presume publicado a mediados de los $70^{4}$; la edición trae un prefacio de Federico Chabod, quien refiere al Partido leninista como la expresión del "príncipe moderno" (la ciencia marxista de la política, según el mismo autor); al igual que la edición

\footnotetext{
${ }^{4}$ Ediciones Pepe difundía, además de toda la literatura que producía el Comintern, autores tales como Nikitin, Marx, Engels, Lenin, Stalin y Althusser.
} 
anterior, no se menciona al autor de la traducción de la obra original y el titular de la edición.

Encontramos también una publicación de las "obras de Gramsci", intitulada: Notas para una teoría del partido político marxista, compuesta de los siguientes apartados: I. La ciencia marxista de la política; II. La estructura del partido político, su determinación histórica y III. Notas varias; esta publicación de 134 páginas no presenta editorial, pero si la mención siguiente: Librería Editorial Comuna Socialista, que supuestamente tenía sedes en Bogotá y Barranquilla; en Bogotá, la publicación era distribuida por la librería de la Universidad Libre y según nota a pie de página: "la publicación era una recopilación de transcripción de textos de Gramsci editados y publicados por la Editorial Lautaro de Buenos Aires"; no aparece fecha de publicación, aunque la edición podría ser de los $70^{5}$.

Empero, para esos años convulsos política y socialmente, aparece en la revista Ideas y Valores del Departamento de Filosofía de la Universidad Nacional - a propósito de Gramsci- el artículo: “El proyecto cultural gramsciano: la reforma intelectual y moral", del intelectual chileno Juan E. García Huidobro (1979) ${ }^{6}$; el autor pretendía en ese artículo:

[...] algunos trazos básicos del pensamiento cultural de Antonio Gramsci (1891-1937). Nos detendremos en su concepto de cultura, su interpretación de la cultura popular y su formulación de un proyecto cultural alternativo, que contempla la elaboración de una nueva cultura y su difusión como ideología de la nueva sociedad. (Huidobro, 1979, p. 3)

Resulta importante mencionar este hecho en la difusión del pensamiento gramsciano dado el carácter académico, así como institucional de la revista, aunque ello no la privaba de publicar en sus páginas los debates teóricos en relación con el marxismo y sus más conspicuos representantes de la época tales como Lukács, Althusser y para el caso colombiano el filósofo Freddy Téllez; acotar, a propósito del artículo, el que su autor retrae de Gramsci su apuesta política desde la cultura y la ideología (esto es, la superestructura), así como lo reclamaba Aricó para el itinerario de Gramsci en la Argentina. Asimismo, por otro lado, no es menos importante del artículo de García Huidobro (1979) el soporte bibliográfico con autores

\footnotetext{
${ }^{5}$ Una edición parecida, por lo menos a nivel de título, aparece en la biblioteca de la Universidad de Antioquia (Medellín); tiene como fecha 1972, publicada por la Editorial Diógenes.

${ }^{6}$ Otras obras del autor tienen como tema la educación, cuyo anclaje analítico se deriva del concepto de "cultura y la ideología de la nueva sociedad"; particularmente desde "el rol del educador": Gramsci: educación y cultura (1983); “Discurso pedagógico de las experiencias de educación popular" (1989).
} 
italianos como Broccoli, Badaloni o Buci-Glucksmann que ya circulaban en los medios intelectuales y académicos en México —incluso, más temprano de lo que sugiere Aricó para la recepción de Gramsci en ese país-.

En cuanto a los eventos que pretendían difundir el "pensamiento de Antonio Gramsci" logramos ubicar uno de ellos a mediados de los 80, denominado: "El legado intelectual de Antonio Gramsci: a propósito del cincuentenario de su muerte" (1987); una de las ponencias del evento la hizo la socióloga María Teresa Uribe de Hincapié, conocedora de la obra de Gramsci ${ }^{7}$.

Para esos mismos años aparecieron dos artículos referidos a Gramsci: uno de ellos, de Camilo Castellanos, "Antonio Gramsci: un hombre medio, poco común y nada corriente"; el otro, "Gramsci en nuestro medio", del profesor Marco Raúl Mejía; ambos publicados en la revista Foro, número 3, julio de 1987.

En 1991, la Corporación Viva la Ciudadanía y Foro por Colombia organizaron en Bogotá el seminario "Gramsci y la realidad colombiana"; el objetivo de la convocatoria al evento tenía que ver, según los organizadores, con el propósito de "generar un debate en torno a las relaciones entre la cultura y la política; la ética y el proyecto democrático; la función de los intelectuales, la recuperación de la sociedad civil, el papel del Estado, el imaginario colectivo de los colombianos" (Suárez, 1987, p. 233).

De acuerdo a los participantes del evento se formularon diversos puntos de vista en las ponencias entre los que destacarían la valoración crítica del pensamiento de Gramsci, el significado de la política, los procesos de paz, el análisis de la cultura democrática y el papel de los intelectuales; era claro para los organizadores que Gramsci significaba: "la renovación democrática y la creación de una corriente de pensamiento que reinterpretara la nueva época y potenciara liberadoramente los nuevos actores sociales y los desafíos del inmediato porvenir" (Suárez, 1987, p. 6-7); se observa en ese caso que dado el ambiente convulso que vivía el país, previo a la convocatoria de la constituyente, así como la emergencia y el protagonismo que venían reclamando otros sectores sociales especialmente los estudiantes gestores de la Séptima papeleta, la perspectiva analítica y conceptual del pensamiento de Gramsci resultaba aleccionadora y ofrecía elementos novedosos frente a esa particular configuración sociopolítica de la realidad colombiana; así pues, Gramsci resultaba oportuno en tanto "permitía explicar la realidad actual, "replantear el pensamiento político,

\footnotetext{
${ }^{7}$ Dicha ponencia apareció publicada en la revista Lecturas de Economía, número 22, enero-abril de 1987; es de anotar que la autora hace explícito su conocimiento de Gramsci, al incorporar su teoría y conceptos - principalmente el de sentido común - en su obra Poderes y regiones: problemas en la constitución de la Nación colombiana, 1810-1850 (1987).
} 
dado el lugar de la sociedad política democrática" (Suárez, 1987, p. 7); todo esto, sin duda, elucidado al tenor del artículo que aparece en la edición de la misma revista que lleva por título "Hegemonía e ideología" de Chantal Mouffe.

En los 90, un gran conocedor y difusor de la obra de Gramsci, Jorge Gantiva, publica la obra Punto de referencia: un ensayo sobre Gramsci: el sentido de la filosofía, de la política y la tarea del pensar (1993); con pretensiones interpretativas en sus aportes para el conocimiento de la realidad y el papel de la educación. En este caso, a manera de intelectual, el profesor incide en esa realidad a transformar; la crítica de Gantiva (1993) tiene que ver con la forma limitada o prejuiciada de asumir a Gramsci en sus aportes y categorías al pensamiento marxista. Advertir que, dada su condición de profesor universitario, Gantiva (1993) logra extraer de la obra de Gramsci el protagonismo de la política; aunque esta, habituados a pensarla desde la estructura, sustrae sus potencialidades como plantearía el pensador italiano.

Ahora, entonces, la política permite reconocer desde la praxis cotidiana el proceso pedagógico como quehacer político. Estas reflexiones hunden raíces más allá de lo que puedan decir o expresar las publicaciones o difusión de la obra gramsciana puesto que su asunción, interpretación y crítica fue clave al final de los 70 e inicios de los 80 como lo dejaría ver el "movimiento pedagógico en Colombia"; movimiento que surgió en 1982, formalizado en el XII Congreso de la FECODE en la ciudad de Bucaramanga; si bien el evento no sustrajo la reivindicación de las condiciones y mejoras socioeconómicas del magisterio, también era cierto que allí "se aceptó el reto de repensar las funciones de la Escuela, el papel de la pedagogía y el liderazgo social e intelectual de los maestros".

Hernández y Mejía (1999), al retraer el evento casi dos décadas después, dirían al respecto:

este acontecimiento social y cultural tuvo también implicaciones en lo relacionado con la identidad de los maestros, quienes a lo largo de las luchas sociales y de confrontación con las políticas estatales tuvieron que pensarse como sujetos políticos, al tiempo que empezaron a reflexionar en torno a las relaciones entre educación, pedagogía y política. (p. 19)

Reiteran, asimismo, el que los movimientos sociales gestaron nuevos modelos de "cultura política a lo largo de su accionar y sus "actores" estructuraron nuevas identidades en ocasiones alternas a las difundidas por el sector dominante" (Hernández y Mejía, 1999, p. 19); era claro, para 
ellos, en su papel como "trabajadores de la cultura" — concepto que amplía la perspectiva del papel del educador en su entorno, a la manera en que lo sugería Gramsci-, que:

al sujeto de la educación este ejercicio de la política más allá de un voluntarismo, lo transforma en un actor de su destino y productor de un saber sobre su práctica, y al hacer visible los micro-poderes y poderes locales, pone en cuestión los imaginarios sociales del poder hegemónico. (Hernández y Mejía, 1999, p. 19)

Se observa, entonces, del anclaje analítico que plantean los autores y promotores del movimiento pedagógico, que está embebido de la comprensión del pensamiento gramsciano: la educación se expresa como una praxis en la que el actor o maestro es capaz de agenciar una actitud política, a pesar de su condición subalterna en las posibilidades de plantearse en actitud contrahegemónica, pues:

la educación popular, como parte de las tareas de transformación de la sociedad, de la escuela y de la pedagogía, en función de los intereses de los relegados y excluidos [...] aquellos, acotan los autores, para quienes las tareas pedagógicas era una forma de lucha cultural que coadyuvaba a la lucha política, desde un pensamiento más de izquierda. Dentro de este panorama las discusiones sobre hegemonía, vanguardias, revisionismos, reformismo, etc., siempre estuvieron al interior del movimiento pedagógico. (Hernández y Mejía, 1999, p. 19)

En relación con la apuesta interpretativa y comprensiva del pensamiento de Gramsci aplicado a algunos temas, casi a finales de los 70, en nuestro medio, aparece el trabajo de Néstor Miranda Canal (1978): La concepción del Estado en la obra de Antonio Gramsci; suponemos, de acuerdo a la revisión preliminar que hicimos, que se trata de una tesis de grado presentada a la Universidad Nacional de Colombia. Finalmente, en 1983, Orlando Pulido Chávez publicaría en la revista Foro el artículo: "Concepto de cultura en Gramsci. Una aproximación antropológica".

\section{Conclusiones}

A propósito de una "geografía del gramscismo en América Latina" (expresión acuñada por Aricó) es claro que el pensamiento gramsciano llegó primeramente a la Argentina: en un momento, dice Aricó (1988), en que "la posesión de la cultura era percibida con un agudo sentimiento de culpa"; y, con Gramsci, por primera vez, "la cultura era colocada allí 
donde debía estar como una dimensión insuprimible de la acción política" (p. 23-24). En efecto, tras largos períodos de hibernación leninista y también stalinista, los partidos comunistas de gran parte de América Latina no solo desalentarían y reprimirían — a su manera, obviamente- cualquier acercamiento al pensamiento trotskista y por derivación al gramscismo. Así pues, entonces, la geografía del gramscismo en América Latina —no obstante, la tozudez de los 'camaradas' — llega a la Argentina seguida de Brasil, México y Chile; países donde expresó, estimo, no solo una postura y expectativas alrededor de la cultura y el papel del intelectual sino que también alentó la discusión sobre los movimientos sociales y la sociedad civil; destacando su importancia al interior de las relaciones sociopolíticas, bien sea de cara al autoritarismo y a las dictaduras propiamente dichas. Como parece coincidir para gran parte de los países receptores de las obras y el pensamiento gramsciano se recogieron las categorías o conceptos clave alrededor de la sociedad civil, el Estado, el bloque histórico y el papel del intelectual, que sin duda dosificaron la praxis política y la interpretación de la realidad latinoamericana.

¿Qué aconteció con la difusión del pensamiento de Antonio Gramsci en Colombia? Es posible plantear tres momentos del gramscismo en Colombia: por un lado, se puede afirmar que a mediados de los 50, Gramsci era replicado o difundido desde la revista Mito; buscando una perspectiva y aliento crítico, a fin de hacer de la literatura y la cultura: 'funcional'. Es decir que operara como una nueva pauta y orientación moral para la sociedad; es de resaltar que esa primera recepción de Gramsci es temprana con relación a lo que acontecía en Argentina, aunque allí Gramsci sería traducido y difundido de una manera mucho más sistemática dos años después.

El segundo momento supone la "presencia de Gramsci en Colombia" a través de la difusión de algunos pasajes brevísimos de su obra, particularmente aquella literatura que se refería al 'Partido'. Estas publicaciones, editadas rústica y episódicamente, tienen origen y propósito político en los primeros años de la década del 60 en un contexto sociopolítico con presencia de la insurgencia armada y la activa y beligerante resonancia de los movimientos sociales. Aquí, cabe advertir, por supuesto, como aconteciera en otras latitudes de América Latina, que la recepción del pensamiento gramsciano fue 'filtrada' a través de Lenin o admitida previa aceptación de los partidos comunistas.

El tercer momento, a mediados de los 80, retoma el pensamiento de Gramsci con dos propósitos bien claros y correlativos entre ellos: en uno de esos propósitos, el gramscismo permite hacer comprensiva la emergencia e importancia que se reclama de la sociedad civil al igual que la emergencia de los "nuevos movimientos sociales" entre ellos el más 
emblemático e importante para la época: el movimiento pedagógico; el otro propósito tenía un carácter académico al reclamar sus posibilidades analíticas e interpretativas desde la historia, la política, la sociología, la antropología y la filosofía. Es decir que Gramsci posibilitaría una postura analítica y conceptual que redefiniría los objetos y las preocupación no solo de las ciencias sociales, sino también para la interpretación de la realidad colombiana.

\section{Referencias bibliográficas}

Aricó, J. (1988). La cola del diablo. Itinerario de Gramsci en América Latina. Caracas, Venezuela: Editorial Nueva Sociedad.

Calderón, F. (1991). Hegemonía y bloque histórico en Bolivia. Nueva Sociedad, 115, 157-163.

Córdova, A. (1991). Gramsci y la izquierda mexicana. Nueva Sociedad, 115, 160-163.

Coutinho, C. (1991). Brasil y Gramsci: variadas lecturas de un pensamiento. Nueva Sociedad, 115,104-113.

Curto, D. (1998). Presentación. En M. Sacristán. El orden y el tiempo. Madrid, España: Editorial Trotta.

Hernández, C. y Mejía, M. (1999). El movimiento pedagógico. Educación y Cultura, 50, 4-17.

Faletto, E. (1991). Qué pasó con Gramsci. Nueva Sociedad, 115, 90-97.

Gantiva, J. (1993). Punto de referencia: un ensayo sobre Gramsci. Bogotá, Colombia: Editorial Kairós.

García, J.E. (1979). El proyecto cultural gramsciano: la reforma intelectual y moral. Ideas y Valores, 55-56, 3-42.

Gramsci, A. (1953). Lettres de la Prison. Paris, France: Les Éditions Sociales.

Gramsci, A. (1956). Literatura funcional. Mito, 1 (6), 408-413.

Gutiérrez, R. (2005). Mito: asomo nacional a la modernidad. Recuperado de http://www.eltiempo.com/archivo/documento/MAM-1626075.

Herrera, A. (2009). Hegemonía y contra-hegemonía. Ayer, hoy y mañana. Primer seminario Internacional Antonio Gramsci. Bogotá, Colombia: Universidad Nacional de Colombia.

Mejía, R. (1987). Gramsci en nuestro medio. Revista Foro, 3.

Suárez, H. (1987). Gramsci y la realidad colombiana. Bogotá, Colombia: Ediciones Foro Nacional por Colombia. 